\title{
Delayed eye and other consequences from exposure to methyl isocyanate: $93 \%$ follow up of exposed and unexposed cohorts in Bhopal
}

\author{
N Andersson, M K Ajwani, S Mahashabde, M K Tiwari, M Kerr Muir, V Mehra, K Ashiru, \\ C D Mackenzie
}

\begin{abstract}
A follow up study three years after exposure to methyl isocyanate in $93 \%$ of exposed survivors and "control" residents in 10 Bhopali communities showed an excess of eye irritation, eyelid infection, cataract, and a decrease in visual acuity among the exposed people. Breathlessness was twice as common in the heavily exposed clusters as those with lower exposure, a trend that could not be explained by different age or smoking patterns (OR 2.05, 95\% CI 1.36-3.08). Case referent analysis of outpatient attendances at Bhopal Eye Hospital, considering patients with severe refractive errors and astigmatism as "controls," showed a $40 \%$ increased risk of trachoma, $36 \%$ increased risk of other lid infections, and $45 \%$ increased risk of irritant symptoms among previously exposed people. "Bhopal eye syndrome" may thus include full resolution of the initial interpalpebral superficial erosion, a subsequent increased risk of eye infections, hyperresponsive phenomena (irritation, watering, and phlyctens), and possibly cataracts. It remains to be confirmed whether this reflects a more generalised disease as a consequence of previous exposure to methyl isocyanate or whether it is only the eye that is affected.
\end{abstract}

TUC Centenary Institute of Tropical Medicine, London School of Hygiene \& Tropical Medicine, London WC1

N Andersson, K Ashiru

Bhopal Eye Hospital, Bhopal, Madhya Pradesh, India

M K Ajwani, S Mahashabde, M K Tiwari

Department of Ophthalmology, St Thomas' Hospital, London

M Kerr Muir

Chattisgarh Eye Hospital, Fafadih, Raipur, Madhya Pradesh, India

V Mehra

Department of Pathology, Michigan State University, East Lansing, MI 48824 USA

C D Mackenzie
The release of methyl isocyanate (MIC) on the night of 3 December 1984 resulted in the death of at least 1700 people, most of them, it is thought, from acute pulmonary oedema resulting from the burns occurring during the exothermic reaction of MIC with the water content of lung secretions and tissues. ${ }^{1-3}$ During this rapid chemical reaction, faster in the liquid than vapour phase, MIC breaks down to methylamine and the toxic dimethyl urea ${ }^{4}$; on its own, MIC is probably capable of alkylating with a variety of tissues containing amino $\left(\mathrm{NH}_{2}\right)$ and hydroxyl $(\mathrm{OH})$ groups. The consequences of this on the human eye were studied in eight clusters of exposed households and two clusters of broadly comparable but unexposed households in Bhopal, where all occupants were first examined by a team of Indian and British ophthalmologists in the two weeks immediately after exposure before the mass exodus from the city that occurred when the plant was restarted a fortnight after the incident. ${ }^{5}$

Despite initial fears, no case of blindness attributable to exposure to MIC was found in the clinical examinations immediately after the disaster. The early eye lesions found in Bhopal survivors, typically a superficial interpalpebral erosion (SIPE) of the cornea and conjunctiva, ${ }^{6}$ appeared to heal without notable scarring within three months. Follow up at one year confirmed this resolution of the initial superficial erosion, but the complaint of excessive watering and irritation was noted during follow up. ${ }^{4}$ Andersson and colleagues studied further the complaint of excessive watering by comparing 989 cases and 532 referents from outpatient records of the Bhopal Eye Hospital. This confirmed that increased risk of irritant eye symptoms was related to duration of exposure to the gas and could not be accounted for by age or social class. The conjunctival epithelium of cases complaining of excessive watering appeared normal on slit lamp examination and no abnormality of tear drainage could be detected using crude duct patency tests. ${ }^{\text {? }}$

Parallel to the epidemiological follow up of the survivors in Bhopal, a toxicological model of the eye damage and other effects was developed by Salmon at the London School of Hygiene and Tropical 
Medicine using Lister hooded rats, in which species the initial eye lesions closely resembled the human lesions observed in Bhopal survivors. ${ }^{89}$ Changes 14 months later included an eosinophilic and lymphocytic infiltrate in the conjunctival mucosa and in the perilimbal regions, more prominent in animals that were more heavily exposed..$^{10} \mathrm{~A}$ subsequent larger study in rats confirmed chronic inflammation of the glands of the eyelids which included cystic changes and degeneration of these organs, alterations that were more pronounced in more heavily exposed animals and which increased with time. ${ }^{11}$

We describe here the three year follow up of eight exposure and two non-exposure clusters in Bhopal and the results of a case-control monitoring scheme established at the Bhopal Eye Hospital immediately after the disaster, which now permit evaluation of accumulating clinical evidence that these eye changes noted in exposed animals may also occur among man.

\section{Methods}

Eight exposed and two unexposed clusters of households, where all surviving residents were examined in the two weeks after the disaster, were followed up over three years. Selection of the clusters and details of the initial examination have been described elsewhere. ${ }^{4-6}$ People examined after the initial two weeks who were not part of the original population of the community eye programme have been excluded from this analysis. Children born to mothers in the original exposure or non-exposure cohorts were included in the analysis, as were people who died in the course of follow up if a "verbal necropsy" from two neighbours or relatives confirmed the likely cause of death.

All examinations followed the same format and were carried out by the same observers. A brief questionnaire was administered in Hindi, inquiring about age, exposure history, main health problems, eye problems, medical treatment, and smoking $\stackrel{5}{\rightarrow}$ habits. The eye examination was detailed, including 0 slit lamp and fundoscopy of all residents of the clusters in the Bhopal Eye Hospital community eye $\frac{\bar{c}}{5}$ programme. One ophthalmologist (MKM) $\stackrel{\mathbb{\Omega}}{\Omega}$ examined nearly $70 \%$ of participants at least twice $\approx$ over the three years. Vision was tested with and without the use of a pinhole; colour vision and $\vec{\circ}$ afferent pupillary reflexes were measured to test for $\overrightarrow{\vec{\omega}}$ damage to the optic nerve. Standard definitions were $\stackrel{\sim}{\circ}$ used to describe opthalmic conditions encountered. Data were analysed using standard statistical procedures. ${ }^{12-14}$

Results of this cluster cohort analysis generated $\infty$ hypotheses for testing on the much larger base of derived from the Bhopal Eye Hospital which, over $42 \mathrm{\omega}$ months, received some 50000 new outpatients. Soon after starting the hospital, which provides relief to $\overrightarrow{ }$ gas exposed victims with eye problems, a record system was inaugurated allowing rapid manual extraction of large series of cases of the eye conditions $\stackrel{\oplus}{~}$ in question to consider their exposure history, age $\vec{\theta}$ and sex, and presenting complaints. Referents (controls) were people from the same community also attending hospital with eye problems who were? found to have a refractive error greater than five diopters or astigmatism (and no other defect). Age and sex were taken into account in the analysis by $\frac{\circ}{\varnothing}$ stratification. Social class is a complicated issue in 2 India and was only taken into account in as much as $\overrightarrow{\vec{O}}$ both cases and referents presented voluntarily at the hospital from the same catchment area complaining of eye problems.

\section{Results}

Table 1 portrays the age and sex distribution of people followed up in the 10 cluster cohorts and

Table 1 Age and sex distribution of 10 cluster cohorts: follow up December 1984-April 1988 (Male/female)

\begin{tabular}{|c|c|c|c|c|c|c|c|c|c|c|}
\hline & \multicolumn{8}{|c|}{ Exposed clusters } & \multicolumn{2}{|c|}{ Not exposed } \\
\hline & 1 & 2 & 3 & 4 & 5 & 6 & 7 & 8 & 9 & 10 \\
\hline \multirow[t]{2}{*}{$\begin{array}{c}\text { Age group }(y) \\
0-9 \\
10-19 \\
20-29 \\
30-39 \\
40-49 \\
50-59 \\
\geqslant 60\end{array}$} & $\begin{array}{c}7 / 7 \\
6 / 3 \\
11 / 17 \\
7 / 0 \\
1 / 2 \\
1 / 1 \\
1 / 2\end{array}$ & $\begin{array}{l}2 / 1 \\
1 / 2 \\
0 / 1 \\
1 / 3 \\
2 / 2 \\
1 / 2 \\
0 / 0\end{array}$ & $\begin{array}{l}11 / 10 \\
4 / 9 \\
3 / 11 \\
4 / 5 \\
0 / 2 \\
4 / 0 \\
1 / 2\end{array}$ & $\begin{array}{l}7 / 9 \\
2 / 2 \\
2 / 7 \\
5 / 5 \\
2 / 1 \\
4 / 0 \\
1 / 3\end{array}$ & $\begin{array}{l}4 / 2 \\
3 / 2 \\
2 / 3 \\
3 / 4 \\
1 / 3 \\
5 / 9 \\
5 / 3\end{array}$ & $\begin{array}{l}0 / 2 \\
5 / 2 \\
1 / 2 \\
0 / 1 \\
2 / 2 \\
0 / 1 \\
0 / 0\end{array}$ & $\begin{array}{r}0 / 0 \\
4 / 1 \\
2 / 0 \\
12 / 3 \\
16 / 2 \\
3 / 1 \\
5 / 0\end{array}$ & $\begin{array}{l}0 / 0 \\
9 / 5 \\
9 / 6 \\
1 / 3 \\
4 / 4 \\
3 / 1 \\
0 / 1\end{array}$ & $\begin{array}{l}7 / 9 \\
7 / 4 \\
3 / 6 \\
3 / 2 \\
3 / 1 \\
1 / 3 \\
0 / 0\end{array}$ & $\begin{array}{l}4 / 1 \\
8 / 4 \\
9 / 8 \\
2 / 4 \\
1 / 1 \\
2 / 3 \\
1 / 0\end{array}$ \\
\hline & $34 / 32$ & $7 / 11$ & $27 / 39$ & $23 / 27$ & $23 / 26$ & $8 / 10$ & $42 / 7$ & $26 / 20$ & $24 / 25$ & $27 / 21$ \\
\hline $\begin{array}{l}\text { Re-examined } \\
\text { Confirmed dead } \\
\text { Not contacted } \\
1984 \text { cohort }\end{array}$ & $\begin{array}{r}66 \\
1 \\
4 \\
70\end{array}$ & $\frac{18}{17}$ & $\begin{array}{r}66 \\
1 \\
2 \\
69\end{array}$ & $\begin{array}{r}50 \\
2 \\
\frac{2}{50}\end{array}$ & $\begin{array}{r}49 \\
1 \\
2 \\
52\end{array}$ & $\frac{18}{18}$ & $\begin{array}{r}49 \\
55\end{array}$ & $\begin{array}{r}46 \\
1 \\
1 \\
48\end{array}$ & $\begin{array}{r}49 \\
2 \\
6 \\
65\end{array}$ & $\begin{array}{r}\frac{48}{6} \\
54\end{array}$ \\
\hline \multicolumn{4}{|c|}{$\begin{array}{l}\text { Total (excluding births) follow up or confirmed death } \\
\text { Total seen at initial study } 1984 \\
\% \text { Completion of follow up }\end{array}$} & \multicolumn{2}{|c|}{$\begin{array}{l}364 \\
379 \\
96 \%\end{array}$} & & & & \multicolumn{2}{|l|}{$\begin{array}{l}99 \\
119 \\
83 \%\end{array}$} \\
\hline
\end{tabular}

Small discrepancies in totals in clusters $1,2,4,5$, and 9 are due to births in these communities. 
Table 2 Eye symptoms in non-, low, and high exposure clusters: follow up December 1984-April 1988 (percentage)

\begin{tabular}{|c|c|c|c|}
\hline Cluster type & $\begin{array}{l}\text { High } \\
\text { exposure } \\
\text { clusters } \\
1,2,4-6\end{array}$ & $\begin{array}{l}\text { Low } \\
\text { exposure } \\
\text { clusters } \\
3,7,8\end{array}$ & $\begin{array}{l}\text { No } \\
\text { exposure } \\
\text { clusters } \\
9,10\end{array}$ \\
\hline $\begin{array}{l}\text { No followed up for } \\
3 \text { years }\end{array}$ & 201 & 161 & 97 \\
\hline $\begin{array}{l}\text { Irritation/burning } \\
\text { withoụt discharge }\end{array}$ & $137\left(68^{\circ}{ }_{0}\right)$ & $85\left(53^{\circ} \%\right)$ & $56(58 \%)$ \\
\hline $\begin{array}{l}\text { Discharge } \\
\text { Discharge and } \\
\text { irritation/burning }\end{array}$ & $\begin{array}{l}4(2 \%) \\
8(4 \%)\end{array}$ & $\begin{array}{l}3(2 \%) \\
4(2.5 \%)\end{array}$ & $\begin{array}{l}2(2 \%) \\
3(3 \%)\end{array}$ \\
\hline $\begin{array}{l}\text { Loss of vision } \\
\text { Loss of night vision }\end{array}$ & $\begin{array}{c}90(45 \%) \\
4(2 \%)\end{array}$ & $\begin{array}{c}53\left(33^{\circ}{ }_{0}\right) \\
8\left(5_{0}^{\circ}\right)\end{array}$ & $\begin{array}{c}29(30 \%) \\
3(3 \%)\end{array}$ \\
\hline
\end{tabular}

Response to question "Do you suffer any eye problems?".

details of the data missing by the end of three years of follow up. Data could not be obtained on only a small proportion of the original cluster cohorts and some $93^{\circ}$. were seen at least once during the three years or had died during the follow up period. Only one person refused follow up examinations, in cluster 5 . Among the 379 original residents in the eight exposed clusters, all but $15(4 \%)$ were examined again or had died during the three years. Among the 119 originally unexposed people, all but $20(17 \%)$ were re-examined during three years of follow up, almost all of them between April and October of the third year.

Eye symptoms reported by people followed up over three years in response to the question "Do you suffer any eye problems?" (table 2 ) indicate an excess

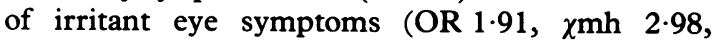
$95^{\circ}$, CI 1.25-2.92) and of the complaint of loss of vision (OR 1.65, $\chi \mathrm{mh} \mathrm{2.29,95 \%} \mathrm{CI} \mathrm{1.075-2.53)}$ among the highly exposed compared with the lower exposed clusters. The complaint of loss of vision was

Table 3 Visual acuity loss ${ }^{\star}$ by age group in the cluster cohorts: follow up December 1984-April 1988. (percentage affected among each age group)

\begin{tabular}{|c|c|c|c|}
\hline Cluster type & $\begin{array}{l}\text { High } \\
\text { exposure } \\
\text { clusters } \\
1,2,4-6 \\
(n=201)\end{array}$ & $\begin{array}{l}\text { Low } \\
\text { exposure } \\
\text { clusters } \\
3,7,8 \\
(n=161)\end{array}$ & $\begin{array}{l}\text { No } \\
\text { exposure } \\
\text { clusters } \\
9,10 \\
(n=97)\end{array}$ \\
\hline $\begin{array}{l}\text { No with loss of visual } \\
\text { acuity }\end{array}$ & $48(24 \%)$ & $22(14 \%)$ & $11(11 \%)$ \\
\hline $\begin{array}{c}\text { Age (y) } \\
0-9 \\
10-19 \\
20-29 \\
30-39 \\
40-49 \\
\geqslant 50\end{array}$ & $\begin{array}{c}1(2 \%) \\
5(18 \%) \\
14(30 \%) \\
16(55 \%) \\
7(39 \%) \\
5(21 \%)\end{array}$ & $\begin{array}{l}3(14 \%) \\
4(13 \%) \\
6(19 \%) \\
5(18 \%) \\
2(7 \%) \\
2(10 \%)\end{array}$ & $\begin{array}{l}0 \\
3(13 \%) \\
0 \\
2(18 \%) \\
5(83 \%) \\
1((11 \%)\end{array}$ \\
\hline
\end{tabular}

* Reduction in visual acuity between two examinations with observers and participants unaware of results of first examination in 1984. Age stratified comparison between higher and lower exposure clusters (OR 2.199, $\chi \mathrm{mh} 1 \mathrm{df} 2 \cdot 9$ ).

Percentages for age specific frequencies are based on numbers examined, reflected in table1. corroborated by formal testing of visual acuity, under conditions where neither subjects nor observers knew the outcome of the baseline 1984 tests (table 3 ). The differential loss in visual acuity between exposed and unexposed people could not be explained by different age structure of the populations. People in the higher exposure clusters were more than twice as likely to suffer deterioration in visual acuity than people in the lower exposed clusters (OR 2.2, $\chi \mathrm{mh} 2 \cdot 9,95 \%$ CI $1 \cdot 29-3 \cdot 75$, stratified for age).

Among the other symptoms volunteered in response to the open question "Do you have any other health problems?" chest pain, breathlessness, and vomiting or nausea were more frequent among exposed than non-exposed people and more common among the heavily exposed than those who lived in clusters that received lower exposure (table 4). The complaint of breathlessness was more pronounced among the more heavily exposed and could not be accounted for by different age structures or smoking habits in the different exposure categories (table 5). Stratifying for age and smoking simultaneously, people in higher exposure clusters were twice as likely to report breathlessness as people in the lower exposure clusters (OR 2.05, $\chi \mathrm{mh} 3.453,95 \% \mathrm{CI}$ $1.36-3.08$ ) and 2.7 times more likely than those in the no-exposure clusters (OR 2.73, $\chi \mathrm{mh} 3.69,95 \% \mathrm{CI}$ $1 \cdot 6-4 \cdot 66)$.

More acute inflammatory trachomatous changes, trachomatous injection (TI) and follicular trachoma (TF), were found among the higher exposure than lower exposure clusters (OR 3.165, $\chi \mathrm{mh} 2 \cdot 11$, $95 \%$ CI 1.085-9.23). In the three years of follow up $5^{\circ}{ }_{0}$ of the unexposed people developed cataracts, whereas $8 \%$ of those with lower exposure and $10 \%$ of those with higher exposure developed cataract. The risk of developing cataract in the higher exposure clusters was nearly twice that in the other groups (OR 1.99, $\chi \mathrm{mh} 2.001,95 \%$ CI 1.014-3.9). There was no new case of altered afferent pupillary reflex or loss of colour vision.

Table 4 Other symptoms in high, low, and non-exposure clusters: follow up December 1984-April 1988. (percentage affected)

\begin{tabular}{|c|c|c|c|}
\hline Cluster type & $\begin{array}{l}\text { High } \\
\text { exposure } \\
\text { clusters } \\
1,2,4-6 \\
(n=201)\end{array}$ & $\begin{array}{l}\text { Low } \\
\text { exposure } \\
\text { clusters } \\
3,7,8 \\
(n=161)\end{array}$ & $\begin{array}{l}\text { No } \\
\text { exposure } \\
\text { clusters } \\
9,10 \\
(n=97)\end{array}$ \\
\hline $\begin{array}{l}\text { Breathlessness } \\
\text { Chest pain } \\
\text { Cough } \\
\text { Vomiting/nausea } \\
\text { Diarrhoea } \\
\text { Headache } \\
\text { Abdominal pain } \\
\text { Weakness/lethargy }\end{array}$ & 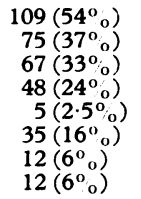 & $\begin{array}{c}57\left(35^{\circ}\right) \\
19\left(12^{\circ}\right) \\
32\left(20^{\circ}\right) \\
7(4 \%) \\
0 \\
10\left(6^{\circ} \%\right) \\
3\left(2_{\%}^{\circ}\right) \\
14\left(9_{\circ}^{\circ}\right)\end{array}$ & $\begin{array}{c}28(29 \%) \dagger \\
20(21 \%) \\
26(27 \%) \\
4(4 \%) \\
0 \\
14(14 \%) \\
5(5 \%) \\
11(11 \%)\end{array}$ \\
\hline
\end{tabular}

*Open response to the question: "Do you have any other health problems?"

$\dagger$ Trend with increasing exposure, $\chi^{2} 22.032 \mathrm{df} p=0.000$. 
Table 5 Breathlessness by age group in the cluster cohorts: follow up December 1984-April 1988. (percentage affected among each age group)

\begin{tabular}{|c|c|c|c|c|c|c|c|c|c|c|c|c|}
\hline \multirow{3}{*}{$\frac{\text { Cluster type }}{\text { No breathless }}$} & \multicolumn{4}{|c|}{$\begin{array}{l}\text { High exposure clusters } \\
1,2,4-6 \\
(n=201)\end{array}$} & \multicolumn{4}{|c|}{$\begin{array}{l}\text { Low exposure clusters } \\
3,7,8 \\
(n=161)\end{array}$} & \multicolumn{4}{|c|}{$\begin{array}{l}\text { No exposure clusters } \\
9,10 \\
(n=97)\end{array}$} \\
\hline & \multicolumn{4}{|c|}{$109(54 \%)$} & \multicolumn{4}{|c|}{$57(35 \%)$} & \multicolumn{4}{|c|}{$28(29 \%)$} \\
\hline & \multicolumn{2}{|c|}{ Smokers } & \multicolumn{2}{|c|}{ Non-smokers } & \multicolumn{2}{|c|}{ Smokers } & \multicolumn{2}{|c|}{ Non-smokers } & \multicolumn{2}{|c|}{ Smokers } & \multicolumn{2}{|c|}{ Non-smokers } \\
\hline Age (y) & $b+$ & $b-$ & $b+$ & $b-$ & $b+$ & $b-$ & $b+$ & $b-$ & $b+$ & $b-$ & $b+$ & $b-$ \\
\hline $\begin{array}{c}0-9 \\
10-19 \\
20-29 \\
30-39 \\
40-49 \\
50-59 \\
60-69\end{array}$ & $\begin{array}{l}0 \\
1 \\
3 \\
6 \\
4 \\
7 \\
3\end{array}$ & $\begin{array}{l}0 \\
0 \\
2 \\
1 \\
0 \\
2 \\
1\end{array}$ & $\begin{array}{r}11 \\
12 \\
24 \\
15 \\
7 \\
9 \\
7\end{array}$ & $\begin{array}{r}30 \\
15 \\
17 \\
7 \\
7 \\
6 \\
5\end{array}$ & $\begin{array}{l}0 \\
0 \\
1 \\
3 \\
0 \\
3 \\
0\end{array}$ & $\begin{array}{l}0 \\
1 \\
3 \\
3 \\
5 \\
4 \\
2\end{array}$ & $\begin{array}{r}12 \\
10 \\
12 \\
7 \\
7 \\
1 \\
1\end{array}$ & $\begin{array}{r}9 \\
21 \\
15 \\
15 \\
16 \\
4 \\
6\end{array}$ & $\begin{array}{l}0 \\
0 \\
0 \\
3 \\
0 \\
1 \\
0\end{array}$ & $\begin{array}{l}0 \\
1 \\
4 \\
4 \\
1 \\
1 \\
1\end{array}$ & $\begin{array}{l}5 \\
4 \\
8 \\
4 \\
1 \\
2 \\
0\end{array}$ & $\begin{array}{r}16 \\
18 \\
14 \\
0 \\
4 \\
5 \\
0\end{array}$ \\
\hline
\end{tabular}

$\mathrm{b}+=$ Breathless; $\mathrm{b}-=$ not breathless.

Stratifying simultaneously for age and smoking:

RR of people with higher exposure compared with lower exposure OR 2.05, $\chi \mathrm{mh} 3.45,95 \%$ CI 1.36-3.08.

RR of people with higher exposure compared with no exposure OR $2 \cdot 73, \chi \mathrm{mh} 3.69,95 \%$ CI $1 \cdot 6-4 \cdot 65$.

RR of people with lower exposure compared with no exposure OR $1 \cdot 53, \chi \mathrm{mh} 1 \cdot 47,95 \%$ CI 0.87-2.69.

The suggestion from the cluster cohort analysis of an association between exposure to MIC and eye infections, irritation, and cataracts was confirmed in the case-referent (case-control) analysis of first attendance outpatients at the Bhopal Eye Hospital. Over the period January 1987 to June 1988, acute infection of the eyelid (blepharitis, chalazion, and sty) was proportionally more common among people exposed to MIC than among those non-exposed. To derive an estimation of relative risk, given that many exposed people attended the hospital for complaints potentially related to MIC, cycatricial trachoma (TC) and tarsal plate involvement (TT) was chosen as a reference entity for acute eyelid inflammation. If these conditions are delayed consequences of exposure then they are unlikely to have developed in the short period since exposure to MIC. This comparison produced a $47 \%$ excess risk of acute lid

Table 6 Signs found by examination of the eye: follow up December 1984-April 1988. (percentage affected)

\begin{tabular}{|c|c|c|c|}
\hline Cluster type & $\begin{array}{l}\text { High } \\
\text { exposure } \\
\text { clusters } \\
1,2,4-6 \\
(n=201)\end{array}$ & $\begin{array}{l}\text { Low } \\
\text { exposure } \\
\text { clusters } \\
3,7,8 \\
(n=161)\end{array}$ & $\begin{array}{l}\text { No } \\
\text { exposure } \\
\text { clusters } \\
9,10 \\
(n=97)\end{array}$ \\
\hline $\begin{array}{l}\text { Trachoma (TI, TF) } \\
\text { Trachoma (TT, TC, CO) } \\
\text { Conjunctivitis } \\
\text { New pterygium } \\
\text { New corneal opacity } \\
\text { New cataract } \\
\text { Loss of visual acuity } \\
\text { Abnormal colour vision } \\
\text { Abnormal afferent } \\
\text { pupillary reflex }\end{array}$ & $\begin{array}{l}15(7 \%) \\
10(5 \%) \\
62(31 \%) \\
8(4 \%) \\
22(11 \%) \\
22(11 \%) \\
48(24 \%) \\
2(1 \%) \\
0\end{array}$ & $\begin{array}{c}4(2 \cdot 5 \%) \\
2(1 \cdot 2 \%) \\
19(12 \%) \\
3(2 \%) \\
6(4 \%) \\
10(6 \%) \\
22(14 \%) \\
0 \\
0\end{array}$ & $\begin{array}{c}2(2 \%) \\
3(3 \%) \\
51(53 \%) \\
7(7 \%) \\
10(10 \%) \\
5(5 \%) \\
11(11 \%) \\
1(1 \%) \\
1(1 \%)\end{array}$ \\
\hline
\end{tabular}

Numbers represent people affected (one or two eyes).

A single subject may present more than one sign.

"New" indicates occurrence during three years of follow up, derived by subtracting signs detected in 1984 .

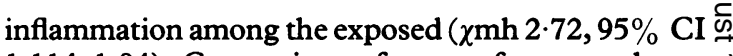
$1 \cdot 114-1.94)$. Comparison of cases of new trachoma $\vec{\bullet}$ (inflammatory and follicular) and advanced tra- $\odot$ choma (TT, TC) illustrated a preponderance of new trachoma among previously exposed people (OR 1.25, $\chi \mathrm{mh} 1 \cdot 99,95 \%$ CI 1.18-1.45). This excess of recent trachoma infection was sustained when severe refractive errors and astigmatism were used as $\frac{2}{\varnothing}$ a reference entity, stratifying simultaneously for age $\bigcirc$ and $\operatorname{sex}($ OR 1.42, $\chi \mathrm{mh} \mathrm{3.83,95 \%} \mathrm{CI} \mathrm{1.19-1.7)} \mathrm{(table} \vec{\circ}$ 7).

Over the same 18 month period, the risk of phlyctenular keratoconjunctivitis was higher among people exposed to MIC than among those nonexposed. Using pterygium, a non-infectious $\stackrel{\mathbb{S}}{\exists}$ conjunctival lesion, as a comparison entity, the $\frac{0}{0}$ relative risk of phlyctens among exposed people was 2.6 times that in non-exposed people (OR 2.64, $\chi \mathrm{mh} \delta$ $2 \cdot 76,95 \%$ CI $1 \cdot 22-5 \cdot 26$ ) when the data were $₹$ stratified for age and sex. There was also evidence 은 that people exposed to MIC were more likely than unexposed people to complain of watering and irritation as a presenting symptom, using the com- N plaint of watering alone as the reference entity $\%$ (OR 1.3, $\chi \mathrm{mh} 6 \cdot 16,95 \% \mathrm{CI} 1 \cdot 18-1 \cdot 45)$ or with $N$ refractive errors and astigmatism (OR 1.5, $\chi \mathrm{mh} 8.66$, N $95 \%$ CI 1.33-1.58) as a reference group, both stratified for age and sex. Although there was no apparent excess relative risk of cataract comparing people of all exposure categories together, there was a $\stackrel{?}{?}$ statistically significant difference between those with 0 higher exposure and those with lower exposure, as 0 portrayed in table $8(\mathrm{OR} 1.3, \chi \mathrm{mh} 3.52,95 \% \mathrm{CI}$ $1 \cdot 23-1 \cdot 5)$, using refractive errors as referents.

\section{Discussion}

The cohort analysis of clusters in the community eye 
Table 7 Case-referent monitoring with hospital outpatient first attendances January 1987-June 1988

\begin{tabular}{|c|c|c|c|c|c|}
\hline & \multirow{3}{*}{$\begin{array}{l}\text { Not } \\
\text { exposed }\end{array}$} & \multirow{3}{*}{$\begin{array}{l}\text { Exposed } \\
\text { to MIC }\end{array}$} & \multicolumn{3}{|c|}{$\begin{array}{l}\text { Relative risk using astigmatism and } \\
\text { refactive errors }\end{array}$} \\
\hline & & & \multirow[b]{2}{*}{ Crude $R R$} & \multicolumn{2}{|c|}{$\begin{array}{l}\text { Age and sex } \\
\text { stratified }\end{array}$} \\
\hline & & & & $R R$ & $95 \% C I$ \\
\hline $\begin{array}{l}\text { Watering only as a presenting symptom } \\
\text { Watering and burning or itching as the presenting symptom } \\
\text { Inflammatory trachoma (TI, TF) } \\
\text { "Old" trachoma (TT, TC, CO) } \\
\text { Phlyctenular keratoconjunctivitis } \\
\text { Pterygium } \\
\text { Conjunctivitis } \\
\text { Sty, chalazion, and blepharitis } \\
\text { Corneal opacity } \\
\text { Corneal ulcer } \\
\text { Glaucoma } \\
\text { Uveal disease }\end{array}$ & $\begin{array}{r}1164 \\
999 \\
191 \\
546 \\
46 \\
168 \\
1000 \\
204 \\
309 \\
48 \\
163 \\
54\end{array}$ & $\begin{array}{r}1954 \\
2704 \\
392 \\
824 \\
90 \\
142 \\
1515 \\
427 \\
355 \\
50 \\
148 \\
52\end{array}$ & $\begin{array}{l}1.1 \\
1.77 \\
1.34 \\
0.99 \\
1.28 \\
0.55 \\
0.99 \\
1.37 \\
0.75 \\
0.68 \\
0.48 \\
0.63\end{array}$ & $\begin{array}{l}1.11 \\
1.45 \\
1.42 \\
1.06 \\
1.24 \\
0.62 \\
1.02 \\
1.36 \\
0.82 \\
0.7 \\
0.69 \\
0.73\end{array}$ & $\begin{array}{l}(1.02-1.21) \\
(1.33-1.58) \\
(1.19-1.7) \\
(0.93-1.2) \\
(0.85-1.8) \\
(0.49-0.78) \\
(0.93-1.12) \\
(1.14-1.62) \\
(0.69-0.97) \\
(0.47-1.04) \\
(0.54-0.88) \\
(0.5-1.03)\end{array}$ \\
\hline
\end{tabular}

was achieved, suggests a threefold excess of eyelid inflammation, twofold increase of new cataracts, and loss of visual acuity among the more severely exposed clusters. Heavily exposed people were twice as likely to complain of breathing problems as people with light exposure, and three times more likely to do so than unexposed people.

Although it was clear who had been exposed and who had not, by virtue of their residence (nonexposed clusters were $11 \mathrm{~km}$ and $14 \mathrm{~km}$ away from the Union Carbide plant), neither examiners nor

Table 8 First attenders at Bhopal Eye Hospital with cataract: Case-referent monitoring, January 1987-June 1988, MIC exposure history, less than or greater than one hour

\begin{tabular}{|c|c|c|c|c|}
\hline \multirow[b]{2}{*}{ Age (y) } & \multicolumn{2}{|c|}{$\begin{array}{l}\text { MIC } \\
\text { Exposure < } 1 \text { hour }\end{array}$} & \multicolumn{2}{|c|}{$\begin{array}{l}\text { MIC } \\
\text { Exposure }>1 \text { hour }\end{array}$} \\
\hline & Cataract & Referent & Cataract & Referent \\
\hline \multicolumn{5}{|l|}{ Men } \\
\hline $0-9$ & 1 & 22 & 2 & 13 \\
\hline $10-19$ & 3 & 142 & 6 & 171 \\
\hline $20-29$ & 7 & 174 & 11 & 211 \\
\hline $30-39$ & 5 & 156 & 12 & 177 \\
\hline $40-49$ & 27 & 188 & 54 & 254 \\
\hline $50-59$ & 73 & 156 & 97 & 192 \\
\hline $60-69$ & 72 & 59 & 125 & 109 \\
\hline $70-79$ & 56 & 36 & 79 & 59 \\
\hline$\geqslant 80$ & 16 & 2 & 34 & 11 \\
\hline \multicolumn{5}{|l|}{ Women } \\
\hline $0-9$ & 0 & 31 & 0 & 11 \\
\hline $10-19$ & 5 & 196 & 2 & 162 \\
\hline $20-29$ & 2 & 227 & 5 & 241 \\
\hline $30-39$ & 14 & 255 & 20 & 307 \\
\hline $40-49$ & 38 & 220 & 76 & 220 \\
\hline $50-59$ & 63 & 155 & 125 & 162 \\
\hline $60-69$ & 81 & 59 & 170 & 104 \\
\hline $70-79$ & 104 & 17 & 73 & 10 \\
\hline$\geqslant 80$ & 20 & 1 & 24 & 4 \\
\hline
\end{tabular}

Stratifying for age and sex simultaneously: estimated odds ratio $=1.299 ;$ Mantel-Haenszel statistic $=3.517 ; 95 \%$ confidence interval $1 \cdot 23-1 \cdot 5$. participants knew how the exposed clusters had been classified as lower and higher exposure. This classification was based on early deaths associated with exposure in these areas, ${ }^{6}$ not on distance from the Carbide plant or on subsquent long term clinical findings. Clusters 1, 2, and 4-6 were classified as higher exposure whereas clusters 3,7 , and 8 were regarded as having a lower exposure. Thus whereas it is impossible to exclude observer or participant bias between exposed and non-exposed clusters, it is highly unlikely that the differences between higher and lower exposure clusters can be explained by this possible observer bias.

The case-referent analysis confirms an excess of recent infections and irritant symptoms in people exposed to MIC. If this phenomenon is limited to the eye it could possibly be explained as iatrogenic. Indiscriminate and long term use of eye drops, including those containing steroids, has been a notable feature since the disaster. It is virtually impossible, under field conditions, to obtain accurate and detailed medical histories on previous use of medication, which makes this plausible explanation difficult to exclude. Almost everyone attending the Bhopal Eye Hospital reports using some previous medication for their eye problems. Yet the findings of continued irritation and recurrent infections in people previously exposed to MIC are in keeping with histopathology from the toxicology experiments, ${ }^{8-11}$ where evidence of dose related and progressive chronic inflammation (eosinophil and lymphoid infiltrates in the conjunctival submucosa and, in the eyelid glands, epithelial dysplasia and chronic inflammatory infiltrates) was found in the absence of any medical treatment. Effects of MIC on the immune system could provide a coherent explanation for the different findings. ${ }^{15}$

In its response to MIC the eye could be considered 
a "sentinel organ" for more general phenomena in the rest of the body. So far, there is no evidence of damage to central or peripheral nerve tissue, as tested in the eye by colour vision and afferent pupillary reflexes. ${ }^{16}$ Fundoscopy, which permits direct appraisal of arteries and veins, has not yet shown any abnormality associated with exposure to MIC. This corresponds with the absence of cardiovascular findings in Salmon's animal toxicology model. ${ }^{8-11}$

The acute superficial interpalpebral erosion is probably similar in chemical nature to the "burns" caused to the lung by the exothermic reaction of MIC with water in mucous secretions. In the eye this lesion heals rapidly, apparently without scarring (tables 6 and 7). Toxicological study of the lungs showed severe and progressive changes including neoplastic and cystic change of the bronchial epithelium, dramatic increases in peribronchial lymphoid tissue, and abnormal syncitialising activity of the epithelium inside pulmonary tissue. ${ }^{11}$ Similar changes in man, if these can be confirmed in postmortem studies, may be related to the complaint of breathlessness in the cluster cohorts, more frequent with increasing severity of exposure and which is not accounted for by smoking or age.

If the apparent excess of cataracts found in this study is confirmed by larger investigations now under way a possible explanation may be found in the dramatic kidney and liver damage found in the toxicological model developed by Salmon. ${ }^{11}$ These effects were more advanced in animals that experienced higher doses of MIC and progressed with time. The apparent increased occurrence of infections, and allergic/inflammatory complaints in the human eye, in the light of increasing evidence of multisystem damage in toxicological models, raises the possibility of generalised systemic long term consequences resulting from exposure to MIC. To exclude this, it is necessary to study formally the occurrence of infections, allergies, and deaths from these conditions. Much light will be shed on the issue when systematic evaluation of human postmortem material from lungs, spleen, liver, and kidneys becomes available.

We acknowledge the support of Dr A K Dube, Dr A Lale, T P Yadav, S K Tiwari, G S Kushwaha, and
$\mathrm{R} \mathrm{K}$ Bagia in the fieldwork and manual analysis of the outpatient data from Bhopal Eye Hospital. The hospital and the community eye care services, from which the clinical records and cluster cohorts were derived, are supported by the Royal Commonwealth Society for the Blind. The opinions expressed in this article, however, are our views and not necessarily those of the Society.

1 Kamat SR, Mahashur AA, Tiwari AKB, et al Early observations on pulmonary changes and clinical morbidity due to the isocyanate gas leak at Bhopal. J Postgrad Med 1985;31:63-72.

2 Dave JM. The Bhopal methyl isocyanate incident: an overview. In: Schiefer HB, ed. Highly toxic chemicals: detection and protection methods. Proceedings of an international symposium, September 1985 Saskatoon Canada. Canada: University of Saskatchewan, Toxicology Research Centre, 1985;1-37.

$3 \mathrm{Karol} \mathrm{MH}$. Respiratory effects of inhaled isocyanates. CRC Crit Rev Toxicol 1986;16:349-79.

4 Andersson N, Kerr Muir M, Salmon A, et al. Bhopal disaster: eye follow up and analytical chemistry. Lancet 1985;i:761-2.

5 Andersson N, Kerr Muir M, Mehra V. Bhopal eye. Lancet 1984;ii:1481.

6 Andersson N, Kerr Muir M, Mehra V, Salmon AG. Exposure and response to methyl isocyanate: results of a community based survey in Bhopal. Br J Ind Med 1988;45:469-75.

7 Andersson N, Kerr Muir M, Ajwani MK, Mahashabde S, Salmon A, Vaidyanathan $\mathrm{K}$. Persistent eye watering among Bhopal survivors. Lancet 1986;ii:1152.

8 Salmon AG, Kerr Muir M, Andersson N. Comparison of toxicology and epidemiology for methyl isocyanate at Bhopal. Hum Toxicol 1987;6:410-411. (Abstract.)

9 Salmon AG, Kerr Muir M, Andersson N. Acute toxicity of methyl isocyanate: a preliminary study of the dose response for eye and other effects. Br J Ind Med 1985;42:795-8.

10 Gassert T, Mackenzie C, Kerr Muir M, Andersson N, Salmon AG. Long term pathology of lung, eye and other organs following acute exposure of rats to methyl isocyanate. Lancet 1986;ii:1403.

11 Mackenzie CD, Andersson N, Cameron K, Kerr Muir M, Salmon A, Gassert T. Longer term consequences of methyl isocyanate exposure in Lister hood rats: possible implications for Bhopal disaster victims. Am J Expl Pathol (in press).

12 Mantel N. Chi-square tests with one degree of freedom: extensions of the Mantel-Haenszel procedure. Journal of the American Statistical Association 1963;58:690-700.

13 Mantel N, Haenszel W. Statistical aspects of the analysis of data from retrospective studies of diseases. J Natl Cancer Inst 1959;22:719-748.

14 Oleinick A, Mantel N. Family studies in SLE. J Chronic Dis 1970;22:617-625.

$15 \mathrm{Karol}$ MH, Kamat SR. The antibody response to methyl isocyanate: experimental and clinical findings. Bull Eur Physiopathol Respir 1988;23:591-7.

16 Mergler D, Blain L, Lagacé JP. Solvent related colour vision loss: an indicator of neural damage? Int Arch Occup Environ Health 1987;59:313-21.

Accepted 5 February 1990 